\title{
Criteria for Acceptance of Records of Ambulatory Arterial Pressure Monitoring
}

\author{
Décio Mion Jr, Katia Coelho O rtega
}

São Paulo, SP - Brazil

Ambulatory monitoring of arterial pressure is being used more and more both in clinical practice and research. Criteria for the acceptance of its records are important for the correct interpretation of the results of this procedure.

According to the I Brazilian Consensus for the Use of Ambulatorial Monitoring of Arterial Pressure published in $1993^{1}$, results of this examination are considered valid when they have: a) a minimum of 80 valid readings within $24 \mathrm{~h}$; b) a deletion index of the readings lower than $20 \%$; c) periods of less than $2 \mathrm{~h}$ without valid measurements.

In contrast, the II Brazilian Consensus for the Use of Ambulatorial Monitoring of Arterial Pressure published in $1997^{2}$ determined that an examination may be considered valid for interpretation when it fulfills the following criteria: a) a minimal duration of $21 \mathrm{~h}$; b) a minimum of three valid measurements/h of patients in the waking state and two valid measurements/h during the sleeping period; c) less than $20 \%$ of either manual or automatic exclusions, or both.

Based on this information, we analyzed the quality of 100 procedures performed in the outpatient clinic of the Hypertension League of the Clinics Hospital. Based on the criteria of the I Consensus, the results of 21 examinations were considered invalid for interpretation for the following reasons: a) less than 80 valid readings: 16 ; b) $\geq 20 \%$ deletions and less than 80 valid readings: 4 ; c) less than 80 valid readings and $\geq 2 \mathrm{~h}$ without measurements: 1 .

However, based on the criteria proposed at the II Consensus, 94 exams were considered invalid for adequate interpretation due to the following reasons: a) less than three valid measurements/h obtained in the waking state or two valid measurements/h obtained during sleep: 90 , or both; $\geq 20 \%$ deletions plus less than three valid measurements/h during the waking state or two valid measurements during sleep: 4 , or both.

Thus, by using the criteria of the II Consensus, the great majority of the examinations would be of inadequate technical quality with an indication for repetition, rendering the method nonviable in terms of cost and acceptability.

In the face of the discrepancies observed when considering the criteria proposed on the I and the II Consensus respectively, we suggest that records showing on average at least three valid measurements during the waking condition and two valid measurements during sleep; should be considered acceptable. Using this criterion, only seven of the 100 exams performed in the outpatient clinic of the Hypertension League of the Clinics Hospital would not be accepted. Our suggestion is based on the study made by Thijs et al. ${ }^{3}$, who verified, using records with readings made every $7.5 \mathrm{~min}$ during the day and every 15 min during the night as references, that arterial pressure should be determined at least at 30 min intervals during $24 \mathrm{~h}$ to get estimates of the majority of the parameters of the diurnal profile of the pressure agreeing within $25 \%$ with the closest maximal variation.

Therefore, we consider it appropriate to suggest that the next Consensus for the Ambulatorial Monitoring of Arterial Pressure should recommend tracings to be accepted when having, on average at least three valid measurements/ $\mathrm{h}$ taken during the waking condition and two valid measurements/h taken during sleep.

\section{References}

1. I Consenso Brasileiro para o Uso da Monitorização Ambulatorial da Pressão Arterial. J Bras Nefrol 1993; 15(I): 6-13.

2. II Consenso Brasileiro para o Uso da Monitorização Ambulatorial da Pressão Arterial. J Bras Nefrol 1997; 19(I): S2-S15.
3. Thijs L, Staessen J, Fagard R, Zachariah P, Amery A. Number of measurements required for the analysis of diurnal blood pressure profile. J Hum Hypertens 1994; 8: 239-44. 